\title{
Anatomical Characteristics of the Bones of the Thoracic Limb of White-Eared Opossum (Didelphis albiventris)
}

\author{
Características Anatómicas de los Huesos del Miembro Torácico \\ de la Zarigüeya Oreja Blanca (Didelphis albiventris)
}

Guilherme Pereira Chiarello; Silvio Pires Gomes; Tais Harumi De Castro Sasahara \& Maria Angélica Miglino

ChIARELlO, G. P.; PIRES GOMES, S.; HARUMI DE CASTRO SASAHARA, T. \& MIGLINO, M. A. Anatomical characteristics of the bones of the thoracic limb of white-eared opossum (Didelphis albiventris). Int. J. Morphol., 39(2):416-422, 2021.

SUMMARY: The skeleton of the thoracic limb is one of the key aspects for the understanding of the habits and movement of different mammalian species. Considering the gap about studies related to marsupial osteology, this work proposes to study the aspects inherent to the skeleton of opossums, with emphasis on the detailed anatomical description of the bones that form the thoracic limb. For this purpose, the bones of six specimens of possums of the species Didelphis albiventris were used. These small to medium sized marsupials inhabit a wide range of South America, living in several types of habitats, being commonly described as arboreal omnivores and have anthropic habits. For the execution of this study, the bone accidents perceptible in the specimens were identified by superficial palpation, which were then radiographed. The thoracic limb bones were prepared by boiling and drying in the sun. Finally, from the radiographic images and the prepared bones, a detailed description of the anatomy of the bone components of the thoracic limb of Didelphis albiventris was made, joining the previously obtained data of surface anatomy. These data were compared with data from the literature, discussing the functional significance of the osteological findings of the thoracic limb of Didelphis albiventris.

KEY WORDS: Animal Anatomy; Marsupial; Osteology; Wild Animals.

\section{INTRODUCTION}

The morphological aspects related to the skeleton are very well known in euterium animals, especially in domestic animals (Dyceet al. 2019) and in humans (Drake et al., 2010). In contrast, there are few details about the skeletal morphology of marsupials, with works such as those of Maier (1987, 1989) and Abdala et al. (2001) being some examples. Other published researches in the area focus on an estimated study of the age of animals from morphometric or dental parameters (Lowrance, 1949; Bergallo \& Cerqueira, 1994; Gardner et al., 2005), or morphometric relations associated with sexual dimorphism (Astúa, 2010). However, there is a gap about research that better elucidates the complete descriptive characteristics of the macroscopic anatomy of the skeleton of these mammals, in particular the limbs and their characteristics.

One of the most common marsupials in the Brazilian territory is the white-eared opossum, Didelphis albiventris.
They are small to medium sized animals, with black-gray coat on the body, black on the tail and white on the ears and face, and have a black stripe on the head and black spots around the eyes (Cáceres, 2001).

The white-eared opossum is a versatile animal with respect to its habitats and can live in meadows, mountains, woods and forests, and is also found in urban environments. The variation of habitats depends on humidity, water availability and temperature conditions (Lemos \& Cerqueira, 2002; Mitchell, 2014). It is commonly found in tropical and subtropical regions of South America, being part of the local fauna of Argentina, Paraguay, Uruguay, Bolivia and Brazil (Tocchio et al., 2015). In general, they have solitary and nomadic habits, being a digger animal (Mitchell). Thus, they can live in groups inside holes, but also next to garbage and in empty human structures, having typically anthropic habits (Cáceres, 2000). 
There are different types of works in the bibliography involving analysis of aspects related to Didelphis albiventris. However, most of these studies involve clinical, therapeutic and/or anesthetic aspects, such as the studies by da Silva $e t$ al. (2017) on parasite infection in D. albiventris and by Waxman et al. (2018) on immobilization of this species. The few papers more focused on morphology of this species are dedicated to the study of non-fossil structures, such as the work of Schäfer et al. (2017) on the structure of the tongue of this animal. In this way, a scientific importance of the study of this species is realized, but with a reduced volume of data about the morphology of the appendicular skeleton of this animal.

\section{MATERIAL AND METHOD}

The methodology consists of two distinct parts: the collection and preparation of opossum bones, and the anatomical analysis (which encompasses the study of surface anatomy, radiographic images and macerated bones). For both stages of the study, cadavers of opossums of the genus Didelphis albiventris will be used, which will come from run over and/or accidents registered in the streets and highways of the central region of the state of Rio Grande do Sul, being duly collected with the SISBio authorization obtained from the Brazilian Institute of Environment and Renewable Natural Resources (IBAMA), number: 64495.

Six adult specimens were collected, three male and three females, from $D$. albiventris. After collection, these animals were stored in a freezer for conservation until analysis began. All specimens were collected on highways and surroundings during 2019, in the vicinity of the UFSM campus - Santa Maria, RS.

Surface Anatomy: Initially, right after the collection of the adult specimens, bone aspects perceived through palpation on the skin in regions with no alterations due to cause mortis were analyzed and can be considered as reference points. These aspects were noted for later description of the palpable bone aspects on the skin.

Specimen Radiographs: After superficial analysis of the bone elements in the specimens, radiographic images were taken on the latero-lateral axes in order to better evidence the bone structures of the thoracic limb before the mechanical preparation of the bones was performed. To be radiographed, the two specimens that had a lower degree of injury derived from the cause mortis were chosen, aiming at a higher content of adequate information about the skeleton.
The radiographs aim to show the organization of the skeleton "in situ", showing the relationship of the bones between them, allowing a more applied analysis about the anatomical aspects of $D$. albiventris, approaching the veterinary clinical practice by bringing a description of how the bones of the thoracic limb of this species of marsupial through one of the main tests for diagnosis of bone changes.

Macerations and Preparation of Skeletons: For the detailed analysis of the anatomical characters, the preparation of the bones of the Didelphis albiventris specimens was started so that the bone details could be appreciated. The same protocol was recommended for all prepared specimens: the thoracic limb was separated from the trunk by the section of the thoracic cincture muscle and sternum-clavicular disarticulation. The musculature was removed, and the bones were separated from each other, the scapula and clavicle bones and the radius and ulna were kept together with the hand. Subsequently, the process of cleaning and whitening of the bones was initiated through subsequent boiling sessions in $10 \%$ aqueous solution with $200 \mathrm{v}$ hydrogen peroxide. The bones underwent boiling periods of about five to ten minutes and were removed from the boil for removal of soft tissue residue, tendons, and muscles through dissection. After the last boiling session, the bones were exposed to sunlight for complete drying and completion of the whitening process, and a period of 48 hours was sufficient for complete drying of the material.

\section{RESULTS}

The skeleton of the thoracic limb of Didelphis albiventris is composed of two bones that form the thoracic cincture (clavicle and scapula), the humerus bone in the brachial region, the radius and ulna bones in the forearm region, and the constituent bones of the skeleton of the hand - carpal bones, metacarpal bones, phalanges and sesamoids.

Clavicle. The clavicle of $D$. albiventris is an elongated, curved, slightly flattened bone. It articulates medially with the manubrium of the sternum, and laterally with the acromion of the scapula. The sternal end of the clavicle is subtly wider than the acromial end and holds a cartilage for articulation with the clavicular incisura of the sternal manubrium. The body of the clavicle is slightly bumpy. The acromial end articulates with the hamate process of the acromion through a small cartilage. The portion of the clavicle's body can be perceived by skin palpation (Figs. 1 and 4). 


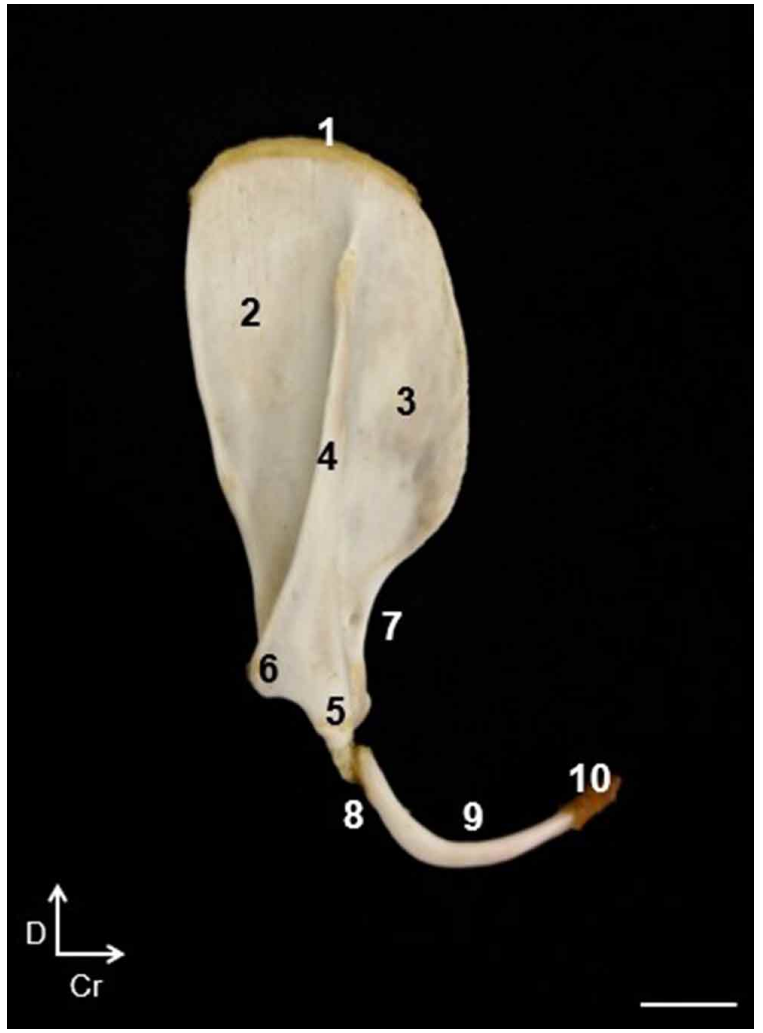

Fig 1. Lateral view of Didelphis albiventris scapula and clavicle. 1. dorsal margin and its complementary cartilage. 2 . infraspinatus. 3. supraspinatus. 4. spine. 5. hamate process. 6. supra-hamate process. 7. scapular incisura. 8. acromial end of clavicle. 9. clavicle body. 10. sternal end of clavicle. Bar $=1$ cm. D. Dorsal. Cr. Cranial.

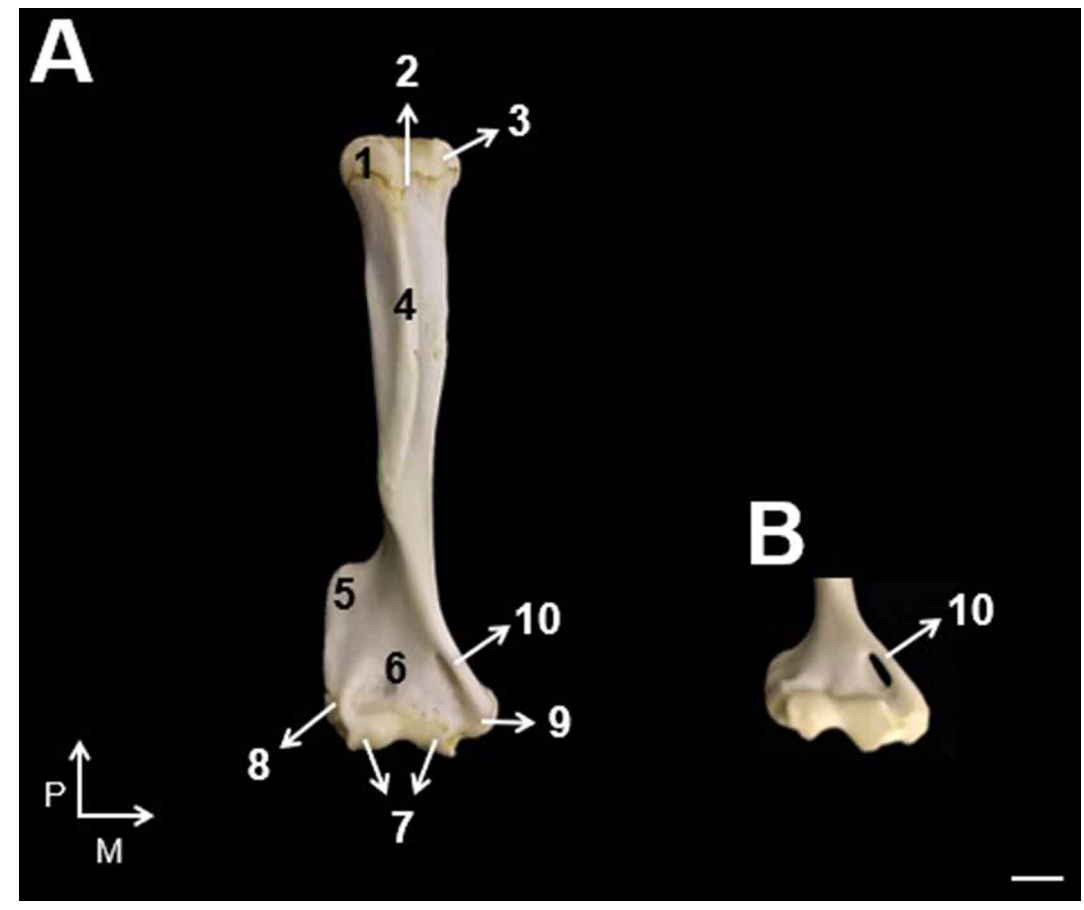

Scapula. This flat bone forms the main bone base of the thoracic cingulate in $D$. albiventris. The scapula is fixed against the chest wall of the trunk by means of the muscles of the cingulate and articulates distally with the clavicle and humerus bones. It has two faces, three edges and three angles. The lateral face has a developed spine and divides this face into two shallow pits of equivalent areas: the supraspinatus fossa (craniodorsal to the spine) and the infraspinatus fossa (caudoventral to the spine). The spine presents a thickening ventrally called acromion. The acromion has a hamate process ventrally, with an articular area for articulation with the clavicle, and dorsally a wide supra-hamate process, which extends caudally over the scapular neck. The medial face of the scapula presents an area dorsally for the insertion of the serratus ventral muscle, which is barely distinguishable from the subscapular fossa located below it. Next to the scapular neck there is a large nutritional foramen, located in the area for the origin of the greater teres muscle, which is subtly delimited.

The tail edge is straight and not hilly. It joins the dorsal edge continuously, forming the caudal angle. The dorsal edge is curved and has a thin cartilage of complementation. This edge continues as the cranial edge after forming the cranial angle. The proximal two thirds of the cranial edge are subtly convex, but its distal third forms an abrupt concavity, called scapular incisura, in the region of the neck. The scapular neck is defined mainly by the scapular notch and separates the ventral angle from the scapula.

The ventral angle is marked by the articular cavity, a shallow glenoid cavity for articulation with the humerus head. This cavity is surrounded by a cartilaginous joint lip. Cranially to the articular cavity lies the supraglenoid tubercle, and caudally the infraglenoid tubercle. The medial side of the supraglenoid tubercle supports a prominent coracoid process, which is curved medially.

The three scapular edges and the scapular spine can be easily recognized by skin palpation (Figs. 1 and 4).

Fig. 2. A. Cranial view of the right humerus of Didelphis albiventris. 1. largest tubercle. 2. intertubercular groove. 3. smaller tubercle. 4. humeral ridge. 5. supraepicondylar crest. 6. radial cleft. 7. condyles. 8. lateral epicondyle. 9. medial epicondyle. 10. supracondylar foramen. B. Detail of the distal epiphysis of the humerus showing the supracondylar foramen. Bar $=1 \mathrm{~cm}$. P. Proximal. M. Medial. 
Humerus. The humerus forms the skeleton of the brachial region, and is a typical example of long bone, presenting a proximal epiphysis, a diaphysis and a distal epiphysis. It articulates proximally with the scapula and distally with the radius and ulna bones.

In its proximal epiphysis there is a large head, which articulates with the glenoid cavity of the scapula. Ventrally to the head is the neck. Laterally and medially to the head are the larger and smaller tubercles respectively. The tubers are separated from each other cranially by a wide intertubercular groove.

The body of the humerus has a twisted appearance due to the groove to the brachial muscle which is located laterally. In the proximal third of this face there is a small round tuberosity, which is ventral to the larger tuber. The lateral side of the humerus body is separated from the cranial side by the marked and prominent humeral ridge, a distal continuation of the larger tubercle. Approximately in the middle third of the diaphysis the humeral ridge ends in a deltoid tuberosity. The distal portion of the lateral face supports a large supraepicondylar crest. The medial side is less bumpy and has a small ridge that continues from the smaller tuber and ends in a larger round tuberosity. Distally, it has an oval-shaped supracondylar foramen, placed over the medial epicondyle.

The distal epiphysis of the humerus supports ventrally two condyles for articulation with the radius and ulna, the lateral condyle for articulation with the ulna, and the medial condyle for articulation with the radius. Dorsally to the condyles there are two pits, the radial fossa being situated cranially, and the olecranon fossa being situated caudally. Next to the condyles are the epicondyles, the medial epicondyle being better delimited, and the lateral epicondyle located ventrally at the supraepicondylar ridge.

The humerus crest and the deltoid tuberosity are easily perceptible on palpation. Parts of the supraepicondylar crest can also be palpated (Figs. 2 and 4).

Radius. The radiusforms the medial part of the skeleton of $D$. albiventris' forearest arm. It has a proximal epiphysis, a diaphysis and a distal epiphysis. It is proximally articulated with the humerus bone, laterally with the ulna, and distally with the bones of the proximal carpal row. At its proximal end is the head, provided with a humeral joint circumference for the joint with the medial condyle of the humerus. Ventrolaterally is the joint face for joint with the proximal end of the ulna. A subtle radial tuberosity is located immediately ventral to this joint face. The diaphysis of the radius is slightly bumpy. Its distal epiphysis presents a triangular, ventrally oriented styloid process. Laterally a joint face is located for articulation with the distal end of the ulna, and ventrally facets are observed for articulation with the radial and intermediate bones of the proximal row of the carpus. By superficial palpation the flat body of the radius can be recognized (Figs. 3 and 4).

Ulna. The ulna articulates proximally with the humerus, medially with the radius, and distally with the bones of the proximal carpal row. It forms the lateral part of the skeleton of the forearm and next to the radius, forms an interosseous antebrachial space that separates the diaphysis of both bones and allows the pronation and supination movements of the hand to be possible. Its proximal epiphysis is called olecranon. The olecranon has a dorsal tuberosity. Cranially it presents an anchoid process, with a concave shape, which continues distally as a semilunar incision. When the humerus and ulna bones are articulated, the anconeal process is located in the olecranon fossa while the semilunar notch articulates with the humerus condyles. Lateral and medial to the semilunar notch are the lateral (which supports the lateral condyle of the humerus) and medial (which articulates with the head of the radius) coronoid processes. Ventrally to the lateral coronoid process there is a reduced ulnar tuberosity. The diaphysis of the ulna is smooth, but slightly more robust than the diaphysis of the radius. The distal epiphysis is wedge-shaped and articulates with the ulnar and accessory bones of the proximal carpal row. It medially presents an area for articulation with the distal epiphysis of the radius, and laterally the styloid process (Figs. 3 and 4).

Hand Bones. The hand of D. albiventris is composed of the associated carpal bones, metacarpal bones, phalanges and sesamoids. The carpus forms the wrist skeleton and is composed of eight small short bones arranged in two overlapping rows, the proximal and distal rows. The proximal row is composed of the radial, intermediate, ulnar, and accessory bones, the accessory carpal bone being the most lateral component. The bones of this row together articulate with the distal epiphysis of the radius and ulna. The distal row is composed of I carpal bone, II carpal bone, III carpal bone and IV carpal bone, the IV carpal bone being the largest and most lateral component. The bones of the distal row articulate with the proximal epiphysis of the metacarpal bones.

The metacarpal bones form the skeleton of the back of the hand and are a set of five small long bones that articulate proximally with the elements of the distal carpal row, and distally with the proximal phalanges. Similar to the distal carpal bones, the metacarpal bones are numbered, the I metacarpal bone being the most medial, and the $\mathrm{V}$ metacarpal bone the most lateral element. Metacarpal bones II, III, and IV are the largest and have similar lengths; the $\mathrm{V}$ metacarpal bone is similar to these but has a relatively shorter length. The I metacarpal bone is also shorter, but it is the widest metacarpal 
bone. All metacarpal bones have a proximal epiphysis, called the base, and a distal epiphysis, called the head. The head has a trochlea for joint with the proximal phalanges and palmar sesamoids.

The skeleton of the digits is formed by the phalanges. The hand of $D$. albiventris presents five digits and, except for the first one, all of them present three phalanges denominated proximal, middle and distal phalanx. The first digit, being shorter, presents only the proximal and distal phalanges. The proximal and middle phalanges are anatomically very similar, the main difference being the length: the proximal phalanges are longer. Both the proximal and the middle phalanx appear base and head with trochlea, similar to the metacarpal bones. In general, there are no differences in the length of the proximal or middle phalanges with respect to the different digits. The base of the proximal phalanges articulates with the trochlea of the corresponding metacarpal bone, and the head of the proximal phalanx articulate with the base of the middle phalanx. The head of the middle phalanx articulates with the articular face of the distal phalanx.

The distal phalanges are more complex than the proximal or middle phalanges and have unique anatomical structures. Cranially, the distal phalanges support a developed ungual process, which serves as the bone base for the fixation of the claws. The extensor process is located dorsally on the joint face with the middle phalanx. Medially, the solar foramen is located at the root of the nail process. Ventrally, a small flexor tuber may be perceptible, situated caudally to the nail process.

Five pairs of palmar sesamoids, one pair for each digit, can be observed on the palmar side of the joint between the metacarpal bone and the proximal phalanx. These sesamoids articulate proximally with the trochlea of the metacarpal bone, and distally with the base of the proximal phalanx. A small carpal sesamoid, located dorsally to the radial bone of the carpus, can still be observed in the hand of $D$. albiventris.

By superficial palpation the set of carpal bones can be felt as a whole, the accessory carpal bone being more diagnostic. The diaphysis of the metacarpal bones and the proximal and middle phalanges can also be palpated. The distal phalanx is embedded inside the corneal claw, making palpation impossible (Figs. 3 and 4).

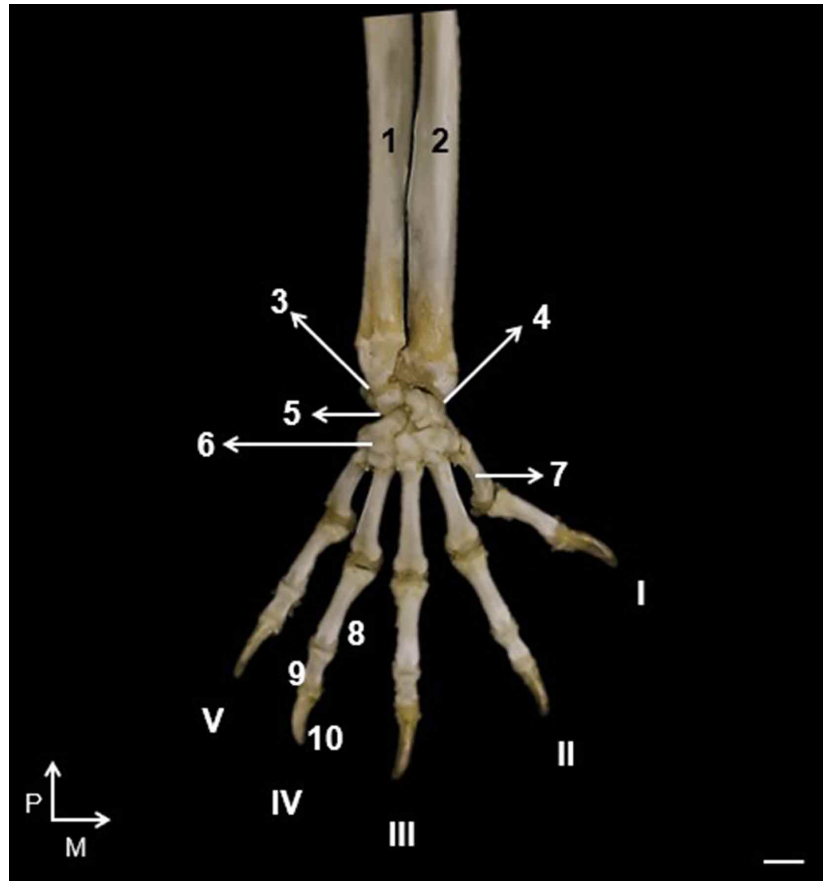

Fig. 3. Dorsal view of the distal half of the radius and ulna bones and the skeleton of Didelphis albiventris hand. 1. body of ulna. 2 . body of radius. 3 . styloid process of the ulna. 4. styloid process of the radius. 5. proximal carpal bones. 6. distal carpal bones. 7. metacarpal bone 8. proximal phalanx. 9. middle phalanx. 10. distal phalanx. I-V. I-V digits. Bar $=1 \mathrm{~cm}$. P. Proximal. M. Medial.

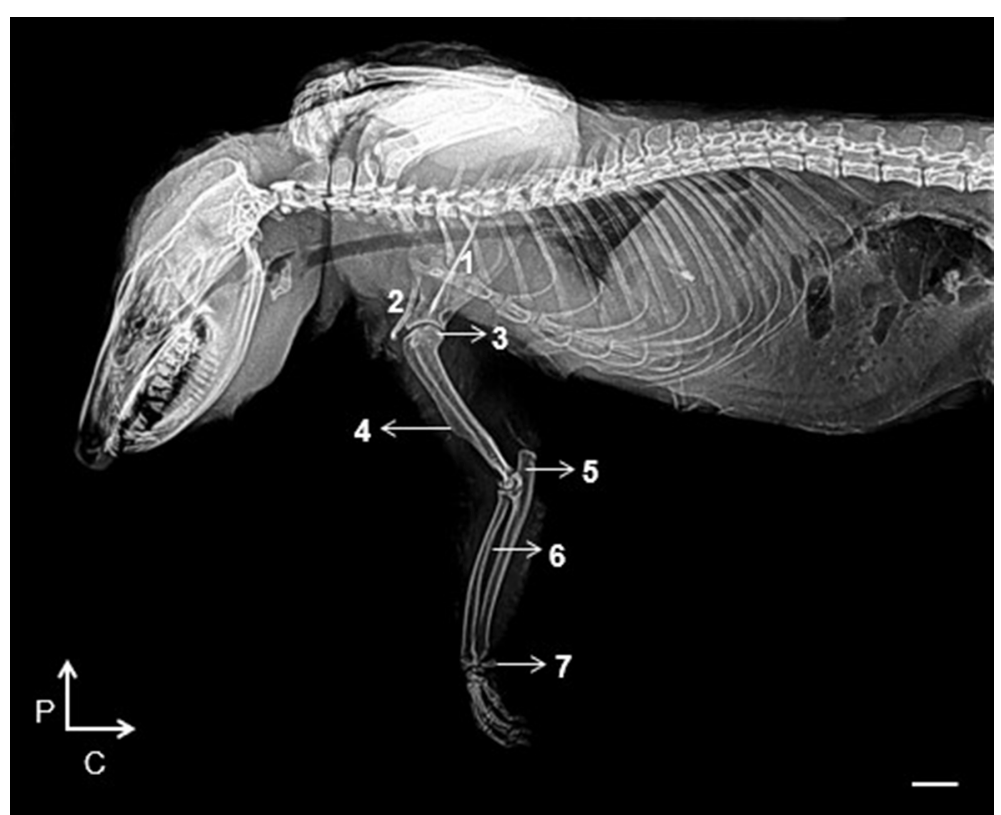

Fig. 4. Radiographic image of Didelphis albiventris in lateromedial projection, showing aspects of the thoracic limb skeleton. 1. scapular spine. 2. clavicle body. 3. humerus head articulating in the glenoid cavity of the scapula. 4. deltoid tuberosity of the humerus. 5. ulna olecranon. 6. antebrachial interosseous space. 7. carpal attachment bone. Bar $=2 \mathrm{~cm}$. P. Proximal. C. Flow rate. Note: The clavicle is disarticulated from the scapular acromion. 


\section{DISCUSSION}

Didelphis albiventris scapula is a typically flat bone, presenting the basic configuration of the mammalian scapula, with two sides, three edges and three angles, and a prominent scapular spine. It presents a developed hamate process, according to what was presented by Olude et al. (2010) for the African giant mouse, and in other rodent species (Hebel \& Stromberg, 1976; Özkan, 2002), and carnivores (König \& Liebich, 2016; Evans \& Delahunta, 2017). The suprahamate process was reported in cats and rabbits (Popesko, 2012; Dyce et al. 2019). Both the hamate process and the supra-hamate process in the scapula of $D$. albiventris indicate the need for a larger area for attachment of the deltoid musculature, relating to muscles proportionally more developed than those found in species whose scapulas do not have such processes. Olude et al. highlight the supraspinatus and infraspinatus pits of the same size in rodents, a fact shared by wombats (Saber, 2013) and $D$. albiventris in this study, indicating a probable similarity in the infraspinatus and supraspinatus muscle area, without a greater functional role of one muscle to the detriment of the other.

The clavicle presented itself as an elongated and welldeveloped bone, articulating with the sternum manubrium, and with the scapular acromion. This joint fixation of the thoracic limb to the trunk, through the sternum-clavicularscapular union is typical of excavator animals, described in rodents and lagomorphs (Olude et al.; Popesko), which, like opossums, use the movement of the thoracic limb to dig, and need a greater stabilization of the shoulder to perform such movements. Due to its presence, the clavicle also allows the fixation of more muscle groups that act on the shoulder (Lien, 2013), allowing a more vigorous movement, facilitating the act of digging these animals.

The anatomy related to the humerus bone of $D$. albiventris reflects a bone with a robust design, adapted to fossological habits. It is marked by a prominent humeral crest, such as wombats (Saber) and the mouse (Olude et al.). The presence of a developed humeral ridge reflects a greater insertion of pectoral muscle fibers, indicating a greater potential for thoracic limb adduction. A protruding lateral supraepicondylar ridge is noticeable, in accordance with other fossil species (Saber), and indicates a greater volume of extensor and flexor musculature of the hand and digits, in accordance with the pattern of excavator movement and its need for muscle strength (Lien). A supracondylar foramen present at the distal end of the humerus is also found in cats (Dyce et al., 2019) and other cats, in addition to lagomorphs (Popesko) and in wombats (Saber). This foramen is related to the differentiated path of the median nerve and brachial artery in these species (Kardong, 2017; Dyce et al.).

The radius and ulna bones in D. albiventris are long bones and not fused together, as in wombats (Saber), dogs (Konig et al. 2016; Evans \& Delahunta) And Cats (Dyce et al.); and differing from rats that have these fused bones (Olude et al.). The non-fusion between radius and ulna allows the opossums to move one bone over the other, allowing the pronation and supination movements of the hand. Considering the excavating habits of $D$. albiventris, these movements are particularly useful for the movement of the animal. Similarly, the presence of a protruding olecranon in $D$. albiventris allows the insertion of a more powerful triceps brachial muscle, which increases the extension force of the elbow (Lien), assisting in the digging and climbing habits of these animals.

The hand of possums D. albiventris is well developed, presenting five functional digits. The anatomy related to the skeleton of the hand of these animals is directly related to the grasping and digging capabilities, allowing the opossums to climb trees, hold branches firmly and dig burrows. The carpal region presents itself as a set of eight small bones that, together, allow a biaxial movement of the wrist, ensuring good mobility by hand of these animals. The pattern of carpal bones organization in two rows is also observed in dogs (Evans \& Delahunta), horses and ruminants (Dyce et al.), rodents (Olude et al.) and wombats (Saber). The five metacarpal bones are well developed, the I metacarpal being the shortest in length, according to the dogs (Evans \& Delahunta). The anatomy of the phalanges is similar to that described for dogs and cats (Dyce et al.). The presence of two phalanges in the I digit and three phalanges in the digits II, III, IV and V was also described for rabbits (Popesko) and domestic carnivores (König \& Liebich; Evans \& Delahunta). The wedge shape of the distal phalanx ungual process indicates an adaptation to the fossil habit (Olude et al.; Saber), and its presence in $D$. albiventris demonstrates an adaptation of these animals to burrow and shelter excavation.

In conclusion, the opossums of the species Didelphis albiventris can be recognized as animals of arboreal and fossorial mobility, thanks to several characteristics found in the constituent bones of the thoracic limb of these animals. The analysis of the bones of the thoracic limb exposes the presence of crystals, processes, names, among other accidents, which together characterize the white earrings as unique, differentiating them from other mammals with strange habits. Consider differentiation and configuration of these bone accidents, perceive the presence of diagnostic data that can be useful for evolutionary research and clinical surgical approach. es, expanding the anatomical knowledge in relation to wild species. 


\section{CHIARELLO, G. P.; PIRES GOMES, S.; HARUMI DE CAS-} TRO SASAHARA, T. \& MIGLINO, M. A. Características anatómicas de los huesos del miembro torácico de la zarigüeya oreja blanca (Didelphis albiventris). Int. J. Morphol., 39(2):416-422, 2021.

RESUMEN: El esqueleto del miembro torácico es uno de los aspectos clave para el conocimiento de los hábitos y movimientos de las diferentes especies de mamíferos. Considerando los escasos estudios relacionados con la osteología marsupial, este trabajo se propusoestudiar los aspectos inherentes al esqueleto de la zarigüeya, con énfasis en la descripción anatómica detallada de los huesos que forman el miembro torácico. Para ello se utilizaron los huesos de seis ejemplares de zarigüeyas de la especie Didelphis albiventris. Estos marsupiales de pequeño a mediano tamaño habitan una zona amplia de América del Sur, viven en varios tipos de hábitats, se describen comúnmente como omnívoros arbóreos y tienen hábitos antrópicos. Para este estudio se identificaron mediante palpación superficial los accidentes óseos perceptibles en los especímenes, y posteriormente se tomaron imágens radiológicas. Los huesos de los miembros torácicos se prepararon hirviéndolos y secándolos al sol. Finalmente, a partir de las imágenes radiográficas y de los huesos preparados, se realizó una descripción detallada de la anatomía de los componentes óseos del miembro torácico de Didelphis albiventris, uniendo los datos de anatomía superficial obtenidos previamente. Estos datos se compararon con datos de la literatura, discutiendo la importancia funcional de los hallazgos osteológicos del miembro torácico de Didelphis albiventris.

PALABRAS CLAVE: Anatomía animal; Marsupial; Osteología; Animales salvajes.

\section{REFERENCES}

Abdala, F.; Flores, D. A. \& Giannini, N. P. Postweaning ontogeny of the skull of Didelphis albiventris. J. Mammal., 82(1):190-200, 2001.

Astúa, D. Cranial sexual dimorphism in New World marsupials and a test of Rensch's rule in Didelphidae. J. Mammal., 91(4):1011-24, 2010.

Bergallo, H. G. \& Cerqueira, R. Reproduction and growth of the opossum Monodelphis domestica (Mammalia: Didelphidae) in northeastern Brazil. J. Zool., 232(4):551-63, 1994.

Cáceres, N. C. Food habits and seed dispersal by the white-eared opossum, Didelphis albiventris, in Southern Brazil. Stud. Neotropical Fauna Environ., 37(2):97-104, 2001.

Cáceres, N. C. Population ecology and reproduction of the white-eared opossum Didelphis albiventris (Mammalia, Marsupialia) in an urban environment of Brazil. Cienc. Cult. (São Paulo), 52(3):171-4, 2000.

da Silva, M. R. L.; Fornazari, F.; de Castro Demoner, L.; Teixeira, C. R.; Langoni, H. \& O’Dwyer, L. H. Didelphis albiventris naturally infected with Hepatozoon canis in southeastern Brazil. Ticks Tick Borne Dis., 8(6):878-81, 2017.

Drake, R.; Vogl, W. \& Mitchell, A. Gray's Anatomia Clínica para Estudantes. $2^{\text {nd }}$ ed. São Paulo, Elsevier, 2010.

Dyce, K. M.; Sack, W. O. \& Wensing, C. J. G. Tratado de Anatomia Veterinária. $5^{\text {th }}$ ed. São Paulo, Elsevier, 2019. pp.872.

Evans, H. E. \& Delahunta, A. Guide to the Dissection of the Dog. $8^{\text {th }}$ ed. Saint Louis, Elsevier, 2017. pp.341
Gardner A. L.; Wilson, D. E. \& Reeder, D. M. Order Didephimorphia. In: Wilson, D. E. \& Reeder, D. M. (Eds.). Mammal Species of the World: A Taxonomic and Geographic Reference. $3^{\text {rd }}$ ed. Maryland, Johns Hopkins University Press, 2005.

Hebel, R. \& Stromberg, M. Anatomy of the Laboratory Rat. Baltimore, Williams and Wilkins Company, 1976. pp.106-32.

Kardong, K. V. Vertebrados - Anatomia Comparada, Função e Evolução. $7^{\text {th }}$ ed. São Paulo, Roca, 2017. pp.787.

König, H. E. \& Liebich, H. G. Anatomia dos Animais Domésticos: Texto e Atlas Colorido. $6^{\text {th }}$ ed. Porto Alegre, Artmed, 2016. pp.824.

Lemos, B. \& Cerqueira, R. Morphological differentiation in the white-eared opossum group (Didelphidae: Didelphis). J. Mammal., 83(2):354-69, 2002.

Lien, K. F. Anatomia Funcional dos Vertebrados. Uma Perspectiva Evolutiva. São Paulo, Cenage Learning, 2013. pp.560.

Lowrance, E. W. Variability and growth of the opossum skeleton. $J$. Morphol., 85(3):569-93, 1949.

Maier, W. Ala Temporalis and alisphenoid in Therian Mammals. In: Splechtna, H. \& Hilgers, H. Trends in Vertebrate Morphology. Stuttgart, Fischer, 1989. pp.396-400.

Maier, W. The Ontogenetic Development of the Orbitotemporal Region in the Skull of Monodelphis domestica (Didelphidae, Marsupialia), and the Problem of the Mammalian Alisphenoid. In: Kuhn, H. J. \& Zeller, U. (Eds.). Morphogenesis of the Mammalian Skull. Berlin, Paul Parey, 1987.

Mitchell, K. J.; Pratt, R. C.; Watson, L. N.; Gibb, G. C.; Llamas, B.; Kasper, M.; Edson, J.; Hopwood, B.; Male, D.; Armstrong, K. N.; et al. Molecular phylogeny, biogeography, and habitat preference evolution of marsupials. Mol. Biol. Evol., 31(9):2322-30, 2014.

Olude, M. A., Olopade, J. O.; Akinloye, A. K. \& Mustapha, O. A. Macroanatomical investigations of the skeletons of the African giant rat (Cricetomys gambianus Waterhouse 1840) II: Fore limb. Eur. J. Anat., 14(1):19-23, 2010.

Özkan, Z. E. Macro-anatomical investigations on the forelimb skeleton of mole-rat (Spalax leucodon Nordmann). Vet. Arh., 72(2):91-9, 2002.

Popesko, P. Atlas de Anatomia Topográfica dos Animais Domésticos. $5^{\text {th }}$ ed. São Paulo, Manole, 2012.

Saber, A. S. Some morphological observation on the thoracic limb bones of the hairy-nosed wombat (Lasiorhinus latiformis, Owen). J. Vet. Anat., 6(2):9-109, 2013

Schäfer, B. T.; Teixeira Filho, A. \& Watanabe, I. S. Ultrastructural analysis of the tongue of White-Eared-Opossum (Didelphis albiventris). Faseb J., 31(Suppl. 1): 577.1-577.1, 2017.

Tocchio, L. J.; Gurgel-Gonçalves, R.; Escobar, L. E. \& Peterson, A. T. Niche similarities among white-eared opossums (Mammalia, Didelphidae): Is ecological niche modelling relevant to setting species limits? Zool. Scr. 44(1):1-10, 2015.

Waxman, S.; Orozco, M.; Argibay, H.; Rodriguez, C. \& Otero, P. Comparison of two protocols for field immobilization of white-eared opossums (Didelphis albiventris). Eur. J. Wildl. Res., 64(4):49, 2018.

Corresponding author:

Maria Angélica Miglino

Department of Surgery

School of Veterinary Medicine and Animal Science

University of Sao Paulo (FMVZ-USP)

Av. Prof. Dr. Orlando Marques de Paiva, 87

Cidade Universitária, CEP: 05508270

Sao Paulo-SP - BRAZIL

E-mail: miglino@usp.br

Received: 28-09-2020

Accepted: $23-11-2020$ 